\title{
Leader Machiavellianism and follower silence
}

\section{The mediating role of relational identification and the moderating role of psychological distance}

\author{
Hakan Erkutlu \\ Nevşehir Hacı Bektaş Veli Üniversitesi, Nevsehir, Turkey, and \\ Jamel Chafra \\ School of Applied Technology and Management (SATM), \\ Bilkent Üniversitesi, Ankara, Turkey
}

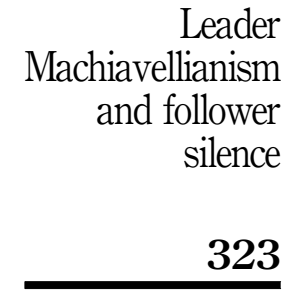

Received 24 September 2018 Revised 14 December 2018 Accepted 18 December 2018

\begin{abstract}
Purpose - Drawing on the social exchange theory, the purpose of this paper is to examine the relationship between leader Machiavellianism and employee's quiescent silence. Specifically, the authors take a relational approach by introducing employee's relational identification as the mediator. The moderating role of psychological distance in the relationship between leader Machiavellianism and quiescent silence is also considered.

Design/methodology/approach - Data were collected from nine universities in Turkey. The sample included 793 randomly chosen faculty members along with their department chairs. Hierarchical multiple regression analysis was conducted to test the proposed model.

Findings - The results of this study supported the positive effect of leader Machiavellianism on employee's quiescent silence as well as the mediating effect of employee's relational identification. Moreover, when the level of psychological distance is low, the relationship between leader Machiavellianism and quiescent silence is strong, whereas the effect is weak when the level of psychological distance is high.

Practical implications - The findings of this study suggest that educational administrators in the higher education should be sensitive in treating their subordinates, as it will lead to positive interpersonal relationship, which, in turn, will reduce workplace silence. Moreover, they should pay more attention to the buffering role of psychological distance for those subordinates with high distrust and showing silence.

Originality/value - This study contributes to the literature on organizational silence by revealing the relational mechanism between leader Machiavellianism and employee quiescent silence. The paper also offers a practical assistance to employees in the higher education and their leaders interested in building trust, increasing leader-employee relationship and reducing workplace silence.
\end{abstract}

Keywords Psychological distance, Relational identification, Leader Machiavellianism, Quiescent silence Paper type Research paper

\section{Introduction}

Employee silence is pervasive in modern organizations and has become an critical issue to organization management (Dyne et al., 2003; Pinder and Harlos, 2001). Employee silence refers to the intentional withholding of information, opinions, suggestions or concerns about potentially important organizational issues (Dyne et al., 2003; Pinder and Harlos, 2001; Wang and Hsieh, 2013). Employee silence reduces organizational commitment, increases corruption (Ashforth and Anand, 2003), impedes innovation at the workplace (Argyris and Schon, 1978) and causes

(C) Hakan Erkutlu and Jamel Chafra. Published in the European Journal of Management and Business Economics. Published by Emerald Publishing Limited. This article is published under the Creative Commons Attribution (CC BY 4.0) licence. Anyone may reproduce, distribute, translate and create derivative works of this article (for both commercial and non-commercial purposes), subject to full attribution to the original publication and authors. The full terms of this licence may be seen at: http://creativecommons.org/licences/by/4.0/legalcode

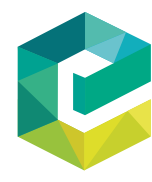

European Journal of Management and Business Economics Vol. 28 No. 3, 2019 pp. $323-342$ Emerald Publishing Limited 2444-8494 
EJMBE

28,3

324

absenteeism, turnover and other undesired behaviors (Carla, 1996). Individuals, who intentionally restrict themselves from communication, suffer from stress and physiological problems (Dedahanov and Rhee, 2015). Employee silence is a dysfunctional behavior for organizations and, as a result, an understanding of the factors that contribute to employee silence has become an important issue in organization management because severely negative organizational consequences can result when managers ignore these factors.

Employee silence is affected by the leader's traits, behaviors and attitudes (Brinsfield, 2013). As a personality trait, Machiavellianism refers to the tendency to manipulate and deceive others in social situations for personal gain (Christie and Geis, 1970). Previous research has shown that leader's Machiavellianism has been linked to organizational deviance and various specific unethical and exploitative behaviors such as tendencies to cheat, lack of workplace integrity and even white-collar crime (O'Boyle et al., 2012). When followers perceive their leaders to be Machiavellian, they are more likely to experience psychological strain, pressure and depression in the workplace, as well as develop negative follower attitudes such as cynicism, turnover intention, low job satisfaction, low commitment and silence (Dahling et al., 2009). In this study, we focus on the process by which leader Machiavellianism affects significant follower outcomes such as employee silence and relational identification. Yet, despite Machiavellianism's long-standing presence in the leadership literature, related research in broad management and applied psychology literature is still in its infancy. To date, no study, to our knowledge, has contributed to an understanding of how leader Machiavellianism relates to employees' quiescent silence, despite the fact that leadership is one of the most influential predictors of employee silence (Brinsfield, 2013; Erkutlu and Chafra, 2018); thus, the first goal of this study is to address this very untapped issue.

In addition, this study investigates psychological distance as the boundary condition for relational identification, i.e. the quiescent silence relationship. Prior researchers have emphasized that leadership and psychological distance significantly influence employee voice behavior (e.g. Milliken and Lam, 2009; Morrison and Rothman, 2009), yet scholars have not considered the interactive effects of leadership trait and psychological distance on silence; i.e. relate to how leadership and organizational members are able to reduce organizational silence (Walumbwa and Schaubroeck, 2009).

The present research is intended to contribute to the existing literature in several ways. First, our research seeks to fill the knowledge gap pertaining to the link between leader Machiavellianism and quiescent silence. Previous research has demonstrated that leadership is one of the most influential factors affecting organizational silence. Therefore, this paper is designed to be one of the first studies to consider the link between leader Machiavellianism and employees' quiescent silence. Second, determining how relational identification decreases employees' quiescent silence has received little empirical attention in the organizational silence-related literature (Umphress et al., 2010). The present study uses social exchange theory as the core theoretical focus and takes a step further to identify the mediating effect of relational identification on the Machiavellianism-silence link. The findings could advance our understanding of the processes by which leader Machiavellianism influences organizational silence. Third, this study contributes to the literature by investigating how leader Machiavellianism enhances followers' quiescent silence via relational identification, which, in turn, accounts for the moderating effect of the psychological distance. Finally, our study adopts a cross-level design and uses a multisource data collection enabling us to provide more robust and meaningful outcomes. Figure 1 summarizes the theoretical model that guided this study.

To test our theoretical model, we selected a context (universities) where employee silence is considered significant. Educational quality has emerged as a major concern in higher education (Sallis, 2014). Proposed strategies for improving educational quality underscore the need for universities to learn from, and prevent the recurrence of errors. In turn, this 


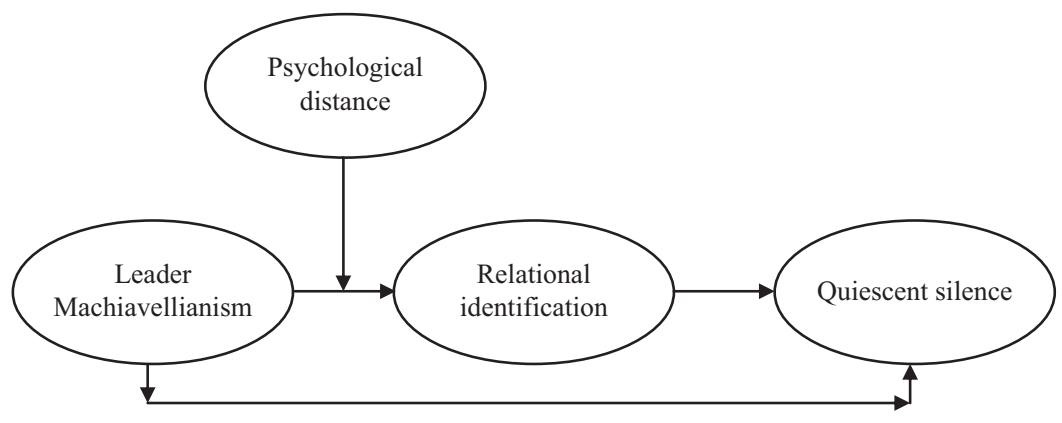

Machiavellianism and follower silence mediation model

requires faculty members in universities to candidly speak up with their opinions and concerns about the problems that their organizations face (Akin and Ulusoy, 2016). Such communication is essential for analyzing the root causes of educational and organizational problems and implementing corrective actions. Yet, even encouraging faculty members to speak up is seen as an essential strategy for improving educational quality, the tendency of faculty members to remain silent about educational and organizational problems observed at work is seen as contributing to errors. For these reasons, the ongoing communication of faculty members on issues affecting the quality of education represents an appropriate context for studying employee silence. Moreover, the relatively hierarchical nature of higher education, where numerous groups (faculty members, administrative staff, technicians, students, etc.) interact to provide optimal service quality, provides a suitable environment to study employee silence since hierarchical organizational structures tend to reinforce workplace silence (Akın and Ulusoy, 2016). Hence, by investigating employee silence in the domain of higher education, we study communicative behaviors pertaining to a critical and an important aspect of a faculty member's work.

\section{Literature review and hypotheses}

\subsection{Leader Machiavellianism and employee quiescent silence}

Employee silence, the intentional withholding of information, opinions, suggestions or concerns about potentially important organizational issues, is a multidimensional construct (Brinsfield, 2013; Milliken et al., 2003). Brinsfield (2013) and Milliken et al. (2003) have suggested that it can be classified into four categories according to reason(s) behind intentional information withholding: acquiescent silence (a disengaged behavior stimulated by resignation), quiescent silence (a self-protective behavior stimulated by fear that the consequences of speaking up could be personally unpleasant), prosocial silence (withholding work-related ideas, information or opinions with the goal of benefiting other people or organization - based on altruism or cooperative motives) and opportunistic silence (information withholding based on opportunism). Acquiescent silence and quiescent silence are often dysfunctional to organizations because they have the potential of interfering with organizational change (Brinsfield, 2013) and suppressing the improvement of organizational performance (Dyne et al., 2003; Tangirala and Ramanujam, 2008). In this study, we focused our attention on quiescent silence because we were mainly interested in the types of employee silence that are of negative consequence to organizations. Prosocial silence, based on altruism or cooperative motives and aiming at benefiting others (Dyne et al., 2003), or opportunistic silence, based on withholding work-related ideas, information or opinions with the goal of achieving an advantage for oneself, were not included in this study because it is often not harmful to organizations. 
EJMBE

28,3

326
In order to understand the negative consequences of leader Machiavellianism, it is useful to consider the components that underlie Machiavellians' behavior. The construct of Machiavellianism is named after the Italian Renaissance Diplomat Niccolo Machiavelli who described in his thesis the ideal yet unethical behavior of royalty to successfully achieve their goals. It was not until the work of Christie and Geis (1970) that Machiavellianism was introduced as a psychological construct. According to these authors, Machiavellianism describes an individual who is a master manipulator, someone who uses aggressive tactics, acts amorally and has an untrusting, negative and cynical view of the world. Due to its manipulative and amoral side, Machiavellianism is usually described in a negative light and has attracted attention in work on organizational behavior (e.g. Belschak et al., 2018; Dahling et al., 2009) as well as business ethics (e.g. Schepers, 2003). People with high Machiavellianism are convincing liars and manipulators, less sensitive to ethical issues and are found in any type of organization, even charitable organizations (Schepers, 2003).

While research on Machiavellianism is still scarce, interesting findings have emerged as to the impact of leader Machiavellianism on others. In fact, Machiavellian leaders have been found to be adaptable to situations, yet detached from their employees' interpersonal concerns. These leaders focus on organizational politics and seek to control employees (Dahling et al., 2009). Studies also show that, generally, Machiavellian leaders rely on deceptive strategies and lie in social relationships (e.g. Geis and Moon, 1981; Gunnthorsdottir et al., 2002). They possess strong persuasive powers in such a way that they can influence others as to run counter to organizational goals and individuals' own pro-social values (Gunnthorsdottir et al., 2002). Machiavellians show a strong goal focus and a lack of feelings of guilt and emotional concerns regarding how to achieve these goals (Christie and Geis, 1970).

Because Machiavellians view the world negatively and ascribe bad intentions to others (Christie and Geis, 1970), employees of Machiavellian leaders find it hard to trust in their leaders. Gunnthorsdottir et al. (2002) found that, as a result of their low trust in relationship partners, employees were significantly less likely to reciprocate during a bargaining game and were the least likely to extend trust first. Such lack of trust worsens when working with a Machiavellianism leader whose employees perceive him/her as being manipulative, deceitful and exploitative than when working with a non-Machiavellianism leader. In particular, the gap between employees' expectations of what they want (e.g. being in control and having the freedom to act the way they want) and what they receive from their Machiavellianism leader (tight monitoring, a wary and distrusting leader) may be too disparate for the development of a trusting or healthy relationship. Thus, we predict that Machiavellianism employees trust leader Machiavellianism significantly less than non-leader Machiavellianism. Trust is an essential component in maintaining a healthy social exchange relationship with others (Blau, 1964). It can increase information sharing and cooperation (Solomon and Flores, 2001), relate to performance (Dirks, 2000) and reduce job stress (Vigoda-Gadot and Talmud, 2010).

Scholars suggest that Machiavellian leadership shapes follower behaviors through social exchange processes (Belschak et al., 2018). Social exchange theory proposes that the norms of reciprocity or perceived obligation to return favors undergird many social relationships (Blau, 1964). According to social exchange theory, when followers perceive a leader as caring and concerned for their well-being, they feel obliged to reciprocate that leader's support (Erkutlu and Chafra, 2017). On the contrary, when a leader is motivated to manipulate others in order to accomplish his/her own goals or is perceived to be more abusive (Belschak et al., 2018), more manipulative (Dahling et al., 2009) and less sympathetic (Rauthmann, 2012) by his/ her followers, subordinates see the exchange relationship as imbalanced or exploited. This leads to psychological strain affecting followers' work attitudes and enhances retaliatory behavior (e.g. deviance, O’Boyle et al., 2012) as well as reduced work effort (Dahling et al., 2009). Building on these ideas, Belschak et al. (2018) suggested that Machiavellianism leaders 
engender feelings of distrust and injustice in their followers, and create an organizational environment where followers are more likely to reciprocate with detrimental organizational outcomes including increased emotional exhaustion and silence.

Moreover, distrust in the leader is negatively associated with the self-efficacy of employees (Yang and Mossholder, 2010). In other words, the higher the distrust in the leader, the lower there will be self-efficacy of individuals to make difference in the organization. Therefore, we believe that employees, with higher levels of distrust, tend to have lower levels of self-efficacy preventing them to share their concerns and make difference in their organization whereas individuals, with lower levels of distrust, are more likely to have higher levels of self-efficacy to make change with their suggestions and remain defensively silent. Hence, we propose the following hypothesis:

H1. The perception of leader's Machiavellianism is positively related to employee's quiescent silence.

\subsection{The mediating role of relational identification}

Identity is the core of an individual's psychological self-concept and development. Employee identification with the leader is a follower's relational self-based on close relations with the leader, which is different from a follower's collective self (referred to as social identity) based on the group or organization membership and identification (Kark et al., 2003). Identification with leader usually represents identification in two different ways: one evokes a subordinate's self-concept in the recognition that he or she shares similar values with the leader, the other gives rise to a subordinate's desire to change his or her self-concept so that his or her values and beliefs become more similar to that of the leader (Pratt, 1998). Priming subordinates' relational self-concepts is crucial for leaders to achieve their effects on the subordinates (Kark et al., 2003).

The extent to which a follower will identify with the leader depends on the attractiveness or desirability of this relationship. The more positive the evaluation of the relationship with the leader, the more likely the employee will identify with the leader by including this relationship in his or her definition of self.

Leaders are known to influence follower behavior in part by shaping follower identities (Lord et al., 1999). Lord et al. (1999, p. 167) suggested that "leaders can profoundly influence subordinates' self-concepts, and thereby influence follower behavior and other social processes." We have argued that higher leader Machiavellianism will be associated with lower relational identification with the leader. The latter helps to explain why followers of a leader with high Machiavellianism are less likely to speak up to their leaders. Sluss and Ashforth (2007) argue that with stronger relational identification comes social attraction, interpersonal connection, a feeling of belongingness and openness to influence from the admired and respected identification target (the leader in this case). Followers of a Machiavellian leader, whom they do not identify with, are reluctant to meet that leader's performance expectations. Followers, who do not identify with their Machiavellian leader, feel less comfortable speaking up to that leader about problems due to their perceptions that speaking up is not safe.

When employees perceive that there is unfairness in their interacting process with the leader, or their leader manipulates them in order to accomplish his/her own goals, they lose their belief, in respect and pride in the organization; thereby will be less stimulated to identify with the organization and the leader. This, in turn, halts them to exhibit discretionary (e.g. cooperative) behaviors. Relational identification has been shown to strengthen employees' identification with their organization (Sluss and Ashforth, 2007). This sense of identification encourages employees to consider organizational problems as their own and to realize that their voice on organizational problems will be taken seriously. Consequently, relational identification can motivate employees to break the silence. 
EJMBE

28,3

We propose that relational identification will mediate the relationships between leader Machiavellianism and employee's quiescent silence. Since Machiavellian leaders are less likely to show respect for subordinates, provide them with sufficient information and allow them to voice their concerns, subordinates tend to perceive low relational identification with the leader. Indeed, Zagenczyk et al. (2013) found a negative effect of leader Machiavellianism on subordinates' perceptions of identification with the leader. In addition, research has shown that perceptions of low relational identification in a social exchange mean that subordinates do not reciprocate supervisory trust (Wu et al., 2012). In fact, when subordinates perceive less relational identification in their interactions with their supervisors, they are more willing to withhold relevant ideas, information or opinions as a form of self-protection. Therefore, leader Machiavellianism may increase quiescent silence through its effect on perceived relational identification.

However, we expect a partial rather than a full mediation of perceptions of relational identification in the leader Machiavellianism-quiescent silence relationship. This is because leader Machiavellianism could increase quiescent silence through mechanisms other than relational identification. In fact, leader Machiavellianism may increase employees' anxiety and sense of uncertainty because leaders' punitive behavior is out of employees' personal control and is often unpredictable. Feelings of anxiety and uncertainty have been shown to be associated with high levels of employee silence (Kenworthy and Jones, 2009). Hence, leader Machiavellianism may engender employees' quiescent silence through alternative mediators. Taken together, we propose the following hypothesis:

H2. The positive relationship between leader's Machiavellianism and employee's quiescent silence is mediated by relational identification, such that (a) the greater the leader's Machiavellianism, the lower the relational identification; and (b) the less relational identification, the less employee quiescent silence will be.

\subsection{The moderating role of psychological distance}

Psychological distance encompasses the "psychological effects of actual and perceived differences between the supervisor and subordinate" (Napier and Ferris, 1993, pp. 328-329), including demographic distance, power distance, perceived similarity and values similarity. Empirically, followers have been shown to hold leader psychological proximity as highly beneficial for the receipt of "sensitive and individually-tailored building communication" (Yagil, 1998, p. 172). Yagil (1998) further argued that a socially and physically close leader was better able to serve as a role model of effective workplace behaviors, in addition to being increasingly approachable. Conversely, when the psychological distance between leaders and followers is reduced, a leader's influence and respect may be diminished when followers are more capable of observing perceived leader weaknesses (Odle, 2014). It has also been discussed that proximity to a leader may allow followers to view their superior as more human and fallible, increasing self-identification and trust (Odle, 2014). The way in which trust develops within the supervisor-subordinate relationship is moderated by distance because "the leader's honesty, reliability, and trustworthiness can be directly manifested by the leader and assessed by close followers" (Torres and Bligh, 2012).

Napier and Ferris (1993) suggested that less psychological distance is associated with higher subordinate performance, higher satisfaction and decreased withdrawal. Increased psychological distance has been shown to negatively affect the quality of manager-subordinate relations (Story and Barbuto, 2011) as well as inhibit self-identification and trust development. Bass (1990) noted that distance, generally, has a negative effect on the quality of the supervisor-subordinate exchange and reduces the leader's influence because of the reduced richness of information transmission. Previous research has indicated that leader-member exchange quality is greatly reduced in environments of increased psychological distance (Erkutlu and Chafra, 2016; Odle, 2014). 
The process of maintaining social stability through informal social consensus - known as social exchange (Blau, 1964) - provides a basis for orderly, productive and predictable social systems to thrive. Of considerable importance is the norm of reciprocity, which requires individuals to help (and not harm) individuals who help them (He et al., 2017). Studies of social exchange suggest that individuals who are unwilling to engage in reciprocal exchange prevent the establishment of mutually beneficial and supportive relationships and are likely to become targets of corrective actions, such as silence (Erkutlu and Chafra, 2016; He et al., 2017). We argue that high psychological distance between leader and followers are viewed as a threat to relationship or group functioning because such behavior weakens rather than strengthens social exchange relationships. These leaders are likely to be viewed as social liabilities in the workplace and are targeted for exclusionary actions. Thus, we expect target psychological distance to be positively related to employees' silence.

We expect that psychological distance influences the link between leader Machiavellianism and quiescent silence. The effect of leader Machiavellianism on quiescent silence styles becomes stronger as the psychological distance increases. Given that supervisors are considered the agents of the organization, their treatment of subordinates as well as their psychological distance with subordinates can influence employees' perception of relational identification (Yoon, 2017). When employees have low psychological distance with their immediate supervisor, thus enjoying discretion, support, autonomy and developmental opportunities, they perceive that they are treated with dignity in their interpersonal interactions, such as spoken to politely, without improper remarks or prejudicial statements. On the other hand, when employees have high psychological distance with their immediate supervisor, they may doubt whether they can trust and build a long-term relationship with their leaders as well as perceive low fairness vis-à-vis the interpersonal treatment. Therefore, psychological distance should complement the effects of Machiavellian personality on relational identification. Hence, we hypothesize the following:

H3. Leader Machiavellianism influences employee quiescent silence through its relationship with relational identification, and the indirect effect will be stronger when the leader-follower psychological distance is strong rather than when it is weak.

Combining H1-H3, we propose a moderated mediation model, shown in Figure 1, to test the relationship between followers' perceptions of leader Machiavellianism and quiescent silence; the model incorporates relational identification as a mediator and leader-follower psychological distance as a moderator.

\section{Methods}

\subsection{Participants}

This study's population consisted of faculty members in Turkish universities. The sample of this study included 793 faculty members along with their superiors (department chairs) from 9 universities in Turkey. These universities were randomly selected from a list of 206 universities in the country (The Council of Higher Education Turkey, 2018).

This study was completed in May-June 2018. A cluster random-sampling method was used to select the sample. In this sampling method, first, all the universities in Turkey were stratified into seven strata according to their geographic regions. Then, universities in each stratum were proportionally selected by a cluster random sampling; faculty members working at the selected universities comprised the study sample. A research team consisting of three research assistants visited the universities in this study and received approvals from the deans of economics and administrative sciences, fine arts, science and literature, engineering and education faculties to distribute the questionnaires. Participants were told that the study was designed to collect information on the faculty 
EIMBE

28,3

330

members' quiescent silence levels and perceptions of their department chairs' Machiavellianism in the higher education workforce. They were given confidentially assurances and told that participation was voluntary. The questionnaires were collected immediately.

A randomly selected group of faculty members from randomly selected departments completed the quiescent silence, relational identification and psychological distance scales (76-100 faculty members per university, totaling 793 out of 900 participants). Faculty members' department chairs completed the leader Machiavellianism scale (18-25 department chairs per university, totaling 180). Department chairs reports of leader Machiavellianism were used instead of faculty members' reports in order to avoid same-source bias. In total, 46 percent of the faculty members were female with an average age of 35.12 years whereas 63 percent of the department chairs were male with an average age of 42.23 years. The response rate turned out to be 88.11 percent.

\subsection{Measures}

Leader Machiavellianism. This study employed 16 items from the Machiavellianism Personality Scale developed by Dahling et al. (2009) to evaluate the leader's level of Machiavellianism. Participants rated items on a seven-point Likert scale $(1=$ strongly disagree; $7=$ strongly agree). Sample items include "My department chair is willing to be unethical if he/she believes it will help him/her succeed" and "My department chair enjoys having control over other people." The scale's reliability was 0.80 .

Quiescent silence. It was measured by using five-item quiescent silence scale developed by Parker et al. (2009). Sample items include "I would not want to hurt my career" and "I would not want to be as difficult or rude." All items were measured on a seven-point scale ranging from 1 ("strongly disagree") to 7 ("strongly agree"). Cronbach's $\alpha$ turned out to be 0.93 .

Follower relational identification with the leader. It was measured using the 10-item measurement of identification with the leader developed and validated by Walumbwa and Hartnell (2011). The participants indicated the extent to which they agreed or disagreed with the ten statements about relational identification with the leader, with 1 indicating "strongly disagree" and 7 "strongly agree". Cronbach's alpha for this scale was 0.83 .

Psychological distance. It was measured by using three-item psychological distance scale developed by Napier and Ferris (1993). The statement, "Think about your department chair and how similar he or she is to you, and then respond with your agreement to the following items" preceded the three items: "I feel very similar to my department chair," "My department chair and I share much in common" and "My department chair isn't that different from me." Items loaded onto a single factor with acceptable reliability. All items were measured on a seven-point scale ranging from 1 ("strongly disagree") to 7 ("strongly agree"). The Cronbach's $\alpha$ for this measure turned out to be 0.91 .

Control variables. The demographic factors, age and gender, found to be significantly related to employee silence (Wang and Hsieh, 2013), were controlled. Age was measured in years whereas gender was measured as a dichotomous variable coded as 1 for male and 0 for female.

\section{Results}

\subsection{Preliminary analysis}

Prior to testing the hypothesized relationships, we first conducted confirmatory factor analyses (CFAs) of the proposed model using the AMOS software package (Arbuckle, 2006) to ensure construct distinctiveness among the study's variables. Results showed that the hypothesized four-factor model of leader Machiavellianism, relational identification, psychological distance and quiescent silence, $\chi^{2}=2,498.23, \mathrm{df}=931$; $\mathrm{RMSEA}=0.07, \mathrm{CFI}=0.95$ and $\mathrm{IFI}=0.95$, yielded a better fit to the data than any other models including a one-factor model (i.e. combining all four 
study variables), $\chi^{2}=8,693.45, \mathrm{df}=949$; $\mathrm{RMSEA}=0.019$; $\mathrm{CFI}=0.50$ and $\mathrm{TLI}=0.50$. These $\mathrm{CFA}$ results also provide support for the distinctiveness of the four study variables for subsequent analyses. The poor fit of the measurement model, with a single underlying latent variable, indicates that common method bias, or single-source bias, is not a major concern with our data. Moreover, an explorative factor analysis, enabling us to investigate whether or not one Leader Machiavellianism and follower silence single factor accounts for the majority of the variance in the variables, shows that the first unrotated factor accounts for 18 percent of the variance. Thus, with no factor explaining the majority of the variance, the Harman single-factor test also suggests that common method bias is not a major concern (Podsakoff and Organ, 1986).

Table I shows factor loadings for each scale item, which can be used to assess the measurement model. The matrix shows that all coefficients are greater than 0.6. The factor coefficients presented in Table I indicate homogeneity within scales. Evidence of acceptable validity is also provided in Table I, which shows the average variance extracted (AVE), or average squared loading, for each latent variable. To confirm acceptable validity, each construct should have an AVE greater than 0.5 (Chin, 1998).

\begin{tabular}{|c|c|c|c|c|c|c|c|c|}
\hline Construct & No. of items & Cronbach's $\alpha$ & Variable & $\begin{array}{l}\text { Standardized } \\
\text { factor } \\
\text { loadings }\end{array}$ & $\underset{(t \text {-value })}{\mathrm{CR}}$ & AVE & $\begin{array}{l}\text { Composite } \\
\text { reliability }\end{array}$ & \\
\hline \multirow[t]{16}{*}{ Leader Machiavellianism } & \multirow[t]{16}{*}{16} & \multirow[t]{16}{*}{0.80} & LM1 & 0.79 & - & \multirow[t]{16}{*}{0.53} & \multirow[t]{16}{*}{0.83} & \\
\hline & & & LM2 & 0.80 & $14.03 * * * *$ & & & \\
\hline & & & LM3 & 0.83 & $16.30 * * * *$ & & & \\
\hline & & & LM4 & 0.88 & $14.23 * * * *$ & & & \\
\hline & & & LM5 & 0.80 & $15.19 * * *$ & & & \\
\hline & & & LM6 & 0.90 & $16.01 * * *$ & & & \\
\hline & & & LM7 & 0.75 & $14.09 * * * *$ & & & \\
\hline & & & LM8 & 0.77 & $15.33 * * * *$ & & & \\
\hline & & & LM9 & 0.83 & $14.74 * * * *$ & & & \\
\hline & & & LM10 & 0.85 & $14.09 * * * *$ & & & \\
\hline & & & LM11 & 0.82 & $13.91 * * *$ & & & \\
\hline & & & LM12 & 0.90 & $13.76 * * *$ & & & \\
\hline & & & LM13 & 0.78 & $14.15^{* * * *}$ & & & \\
\hline & & & LM14 & 0.76 & $14.91 * * *$ & & & \\
\hline & & & LM15 & 0.81 & $14.30^{* * *}$ & & & \\
\hline & & & LM16 & 0.86 & $13.99 * * * *$ & & & \\
\hline \multirow[t]{5}{*}{ Quiescent silence } & \multirow[t]{5}{*}{5} & \multirow[t]{5}{*}{0.93} & QS1 & 0.90 & - & \multirow{5}{*}{0.66} & \multirow[t]{5}{*}{0.94} & \\
\hline & & & QS2 & 0.86 & $16.23 * * * *$ & & & \\
\hline & & & QS3 & 0.81 & 16.06 **** & & & \\
\hline & & & QS4 & 0.86 & 15.36 **** & & & \\
\hline & & & QS5 & 0.83 & $15.76 * * * *$ & & & \\
\hline \multirow[t]{10}{*}{ Relational identification } & \multirow[t]{10}{*}{10} & \multirow[t]{10}{*}{0.83} & RI1 & 0.77 & - & \multirow{10}{*}{0.59} & \multirow[t]{10}{*}{0.84} & \\
\hline & & & RI2 & 0.80 & $14.69 * * * *$ & & & \\
\hline & & & RI3 & 0.86 & $14.89 * * *$ & & & \\
\hline & & & RI4 & 0.83 & $14.95 * * *$ & & & \\
\hline & & & RI5 & 0.82 & $14.62 * * *$ & & & \\
\hline & & & RI6 & 0.81 & $14.23 * * * *$ & & & \\
\hline & & & RI7 & 0.79 & $14.36^{* * * *}$ & & & \\
\hline & & & RI8 & 0.80 & 14.06 **** & & & \\
\hline & & & RI9 & 0.77 & $13.95 * * *$ & & & \\
\hline & & & RI10 & 0.78 & $14.13^{* * * *}$ & & & \\
\hline \multirow[t]{3}{*}{ Psychological distance } & \multirow[t]{3}{*}{3} & \multirow[t]{3}{*}{0.91} & PD1 & 0.86 & - & \multirow{4}{*}{0.69} & \multirow[t]{4}{*}{0.93} & \\
\hline & & & PD2 & 0.84 & $17.76^{* * * *}$ & & & $\begin{array}{l}\text { 1able } 1 . \\
\text { Coefficients for the }\end{array}$ \\
\hline & & & PD3 & 0.83 & $17.23^{* * * *}$ & & & $\begin{array}{r}\text { four-factor } \\
\text { fourients or }\end{array}$ \\
\hline Notes: $n=793 . * * * p<0$ & .001 & & & & & & & measurement model \\
\hline
\end{tabular}


EJMBE

28,3

The means, standard deviations and intercorrelations of all the variables are presented in Table II. The correlations of most of the variables were in the expected direction. The control variables were not significantly correlated with the dependent variable (quiescent silence). Furthermore, all the measures showed a high level of internal reliability.

\subsection{Hypothesis tests}

Our hypotheses were tested in two interlinked steps. First, a hierarchical regression analysis was conducted to use the simple mediation model ( $H 1$ and $H 2$ ) of Baron and Kenny (1986). As several methodologists (Hayes and Preacher, 2010; Preacher and Hayes, 2004) have recently recommended a bootstrap approach to obtain confidence intervals (CIs), we also tested the mediation hypothesis using a bootstrapping test and the Sobel test. Second, the overall moderated mediation hypothesis was tested empirically using an SPSS macro designed by Preacher et al. (2007). Through these procedures, we demonstrated that the strength of the hypothesized mediating (indirect) effect of relational identification on the relationship between leader Machiavellianism and quiescent silence is conditional on the value of the moderator (i.e. psychological distance).

Consistent with $H 1$, leader Machiavellianism showed a positive relationship with quiescent silence $(\beta=0.32, p<0.001)$. H2 posited that relational identification mediates the relationship between leader Machiavellianism and quiescent silence. To test our hypothesis regarding the mediating role of relational identification, we adopted the approach suggested by Baron and Kenny (1986). The Baron and Kenny approach was selected because it is a well-established approach (despite its statistical limitations, e.g. LeBreton et al., 2009) to mediation analysis and has been used across a number of recent studies within the management literature (Cokley et al., 2018; Gkorezis et al., 2014; Gkorezis and Bellou, 2016; Farzaneh et al., 2014; Thompson et al., 2017). This mediation test has several important features. First, the independent variable should be significantly related to the dependent variable. Second, the independent variable should have a significant relationship with the mediator. Finally, the mediator should be significantly related to the dependent variables with the independent variables included in the equation. If the first three conditions hold, at least partial mediation is present. If the independent variables have non-significant beta weights in the third step, complete mediation is present.

The result of the test for $\mathrm{H} 1$ satisfied the first condition of mediation. Next, the result of the test for the significant relationship between leader Machiavellianism and relational identification satisfied the second mediating effect criterion $(\beta=-0.33, p<0.001)$. To test the third criterion, we regressed the dependent variable on the mediating variable, controlling for leader Machiavellianism. As reported, relational identification was significant $(\beta=-0.30, p<0.001)$, reducing the coefficient of the effect of leader Machiavellianism on quiescent silence $(\beta=0.06$, ns). Therefore, the result of the mediation analysis suggests that the effect of leader Machiavellianism on employee quiescent silence is fully mediated by employees' relational identification.

Table II.

Means, standard deviations and correlations of studied variables

\begin{tabular}{lrrrrrrr}
\hline Variable & $M$ & SD & 1 & 2 & 3 & 4 & 5 \\
\hline (1) Age (year) & 35.12 & 1.23 & & & & & \\
(2) Gender & 0.46 & 0.54 & 0.03 & & & & \\
(3) Leader Machiavellianism & 3.66 & 0.86 & 0.04 & -0.03 & & & \\
(4) Relational identification & 3.25 & 0.79 & 0.03 & 0.03 & $-0.35^{* * *}$ & & \\
(5) Psychological distance & 3.43 & 0.81 & 0.06 & 0.06 & $0.22^{* * *}$ & $-0.26^{* * *}$ & \\
(6) Quiescent silence & 3.09 & 0.71 & -0.07 & -0.04 & $0.33^{* * *}$ & $-0.31^{* * *}$ & $0.34^{* * * *}$ \\
Notes: $n=793 . * * p<0.01 ; * * * p<0.001$ & & & & & & \\
\end{tabular}


Following the procedure used by Hayes and Preacher (2010), we then tested the significance of the indirect effects using the Sobel test and bootstrapping. The formal two-tailed significance test (assuming a normal distribution) demonstrated that the indirect effect was significant (Sobel $z=2.33, p=0.02$ ). The bootstrapping results confirmed the Sobel test. Specifically, we estimated $95 \%$ bias-corrected CIs for indirect effects by bootstrapping 10,000 samples. Shrout and Bolger (2002) suggested that, if 0 is not in the CI, the researcher can be confident that the indirect effect is different from 0 . In this study, the $\mathrm{CI}$ is from -0.12 to -0.02 , excluding 0 in the $\mathrm{CI}$, suggesting that the indirect effect is statistically significant in our model. Thus, $H 2$ was supported.

H3 predicted that the indirect effect of relational identification between leader Machiavellianism and quiescent silence would be weakened by low leader-follower psychological distance. The results indicate that the interaction term between leader Machiavellianism and leader-follower psychological distance on relational identification is significant $(\beta=0.25, p<0.01)$. To confirm the direction of this interaction effect, we applied conventional procedures for plotting simple slopes (see Figure 2) at one standard deviation above and below the mean of the leader-follower psychological distance measure. As expected, the slope of the relationship between leader Machiavellianism and relational identification was strong for employees who assessed leader-follower psychological distance as high (simple slope $=-0.29, t=3.39, p<0.001$ ), whereas the slope was weak for employees who assessed leader-follower psychological distance as low (simple slope $=-0.01, t=-0.09, p=\mathrm{ns}$ ).

Next, to examine the conditional indirect effect of leader Machiavellianism on quiescent silence (through relational identification) at two values of leader-follower psychological distance, we used an SPSS macro developed by Preacher et al. (2007). Following their recommendation, we set high and low levels of leader-follower psychological distance at one standard deviation above and below the mean score of leader-follower psychological distance. As expected, the indirect effect of leader Machiavellianism on quiescent silence via relational identification was conditional upon the level of leader-follower psychological distance. The indirect effect was stronger (0.07) and significant at a high level of leader-follower psychological distance (CI ranging from -0.12 to -0.02 and not crossing 0 ) but was weaker $(-0.00)$ and insignificant at a low level of leader-follower psychological distance (CI ranging from -0.04 to 0.02 , crossing 0 ). Thus, $H 3$ was supported (Tables III-V).

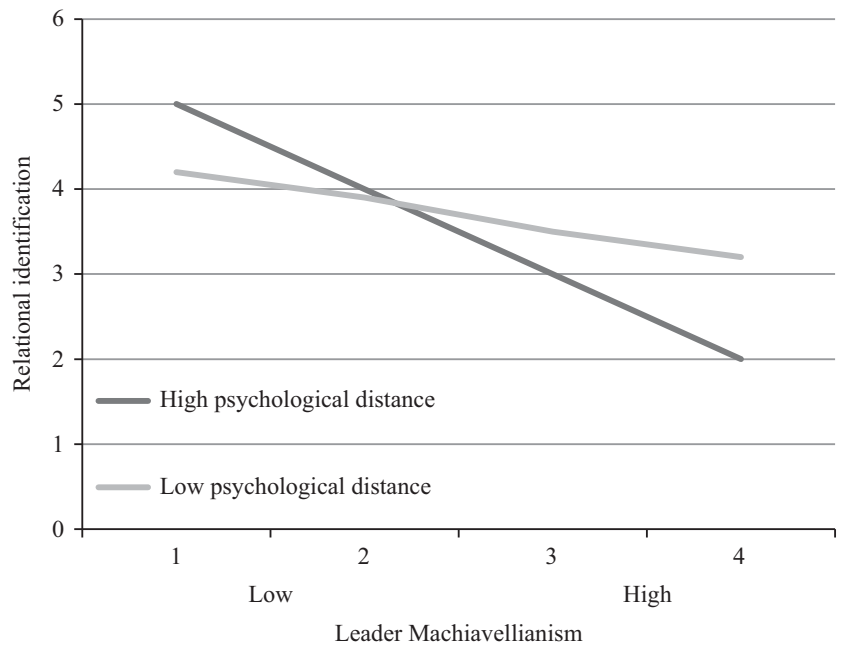

Figure 2. Interaction of leader Machiavellianism and psychological distance on relational identification 
EJMBE

28,3

\section{4}

Table III.

Regression analysis

for testing mediation

\begin{tabular}{lccccc}
\hline & \multicolumn{2}{c}{ Relational identification } & \multicolumn{3}{c}{ Quiescent silence } \\
Variables & Model 1 & Model 2 & Model 1 & Model 2 & Model 3 \\
\hline Age & 0.03 & 0.02 & -0.06 & -0.05 & -0.02 \\
Gender & 0.02 & 0.01 & -0.03 & -0.02 & -0.01 \\
Leader Machiavellianism & & $-0.33^{* * *}$ & & $0.32^{* * *}$ & 0.06 \\
Relational identification & & & & & $-0.30^{* * *}$ \\
Overall $F$ & 0.61 & $3.69^{* * *}$ & 0.33 & $2.09^{* *}$ & $3.89^{* * *}$ \\
$R^{2}$ & 0.04 & 0.13 & 0.02 & 0.05 & 0.06 \\
$\Delta F$ & & $11.19^{* * *}$ & & $7.19^{* * *}$ & $6.21^{* *}$ \\
$\Delta R^{2}$ & & 0.04 & & 0.03 & 0.02
\end{tabular}

Notes: $* * p<0.01 ; * * * p<0.001$

\begin{tabular}{|c|c|c|c|c|c|c|c|c|c|}
\hline \multirow[b]{2}{*}{ Variables } & \multicolumn{4}{|c|}{ Relational identification } & \multicolumn{5}{|c|}{ Quiescent silence } \\
\hline & Model 1 & Model 2 & Model 3 & Model 4 & Model 1 & Model 2 & Model 3 & Model 4 & Model 5 \\
\hline Age & 0.03 & 0.02 & 0.02 & 0.01 & -0.06 & -0.05 & -0.04 & -0.02 & -0.01 \\
\hline Gender & 0.02 & 0.01 & 0.01 & 0.01 & -0.03 & -0.02 & -0.02 & -0.01 & -0.01 \\
\hline \multicolumn{10}{|l|}{ Leader Machiavellianism } \\
\hline (LM) & & $-0.33^{* * * *}$ & $-0.28 * *$ & $-0.15^{*}$ & & $0.32 * * *$ & 0.30 **** & $0.26^{* *}$ & 0.05 \\
\hline Psychological distance (PD) & & & $-0.24 * *$ & -0.20 ** & & & $0.32 * * *$ & 0.30 **** & $0.26^{* * *}$ \\
\hline $\mathrm{LM} \times \mathrm{PD}$ & & & & $0.19 * *$ & & & & $0.27 * *$ & $0.25^{* *}$ \\
\hline Relational identification & & & & & & & & & $-0.29 * *$ \\
\hline Overall $F$ & 0.61 & $3.69 * * *$ & $4.19 * * *$ & 5.66 *** & 0.33 & $2.09 * *$ & $2.71^{* * *}$ & $3.66^{* * * *}$ & $4.15^{* * * *}$ \\
\hline$R^{2}$ & 0.04 & 0.13 & 0.16 & 0.18 & 0.02 & 0.03 & 0.03 & 0.05 & 0.07 \\
\hline$\Delta F$ & & $11.19 * * *$ & $2.89 *$ & 1.69 & & $7.19 * *$ & $7.83^{* * *}$ & $8.12 * * *$ & $8.66^{* * * *}$ \\
\hline$\Delta R^{2}$ & & 0.04 & 0.03 & 0.02 & & 0.03 & 0.02 & 0.01 & 0.01 \\
\hline \multicolumn{10}{|c|}{ Notes: $* p<0.05 ; * * p<0.01 ; * * * p<0.001$} \\
\hline
\end{tabular}

Table V.

Moderated mediation results for quiescent silence across levels of psychological distance

\begin{tabular}{llcccc}
\hline Moderator & Level & $\begin{array}{c}\text { Quiescent silence } \\
\text { Conditional indirect effect }\end{array}$ & SE & LL 95\% CI & UL 95\% CI \\
\hline Psychological distance & High (0.97) & 0.07 & 0.03 & -0.12 & -0.02 \\
& Low (-0.97) & 0.00 & 0.01 & -0.04 & 0.02
\end{tabular}

Notes: LL, lower limit; CI, confidence interval; UL, upper limit

\section{Discussion}

We explored and tested the positive relationship between leader's (department chairs) Machiavellianism and followers' (faculty members) quiescent silence of universities in Turkey. Data from our sample supported our initial hypotheses. Results showed that leader's Machiavellianism is positively associated with followers' silence and negatively associated with relational identification. Furthermore, relational identification provided an explanation of the relationship between leader's Machiavellianism and quiescent silence. In addition, leader-follower psychological distance effectively buffered the negative relationship between relational identification and quiescent silence.

\subsection{Theoretical contribution}

This study extends the research on Machiavellianism in organizations by adding a substantive mediator to explicate how leader's Machiavellianism engenders employees' quiescent silence. 
In doing so, this study provides the insight that relational identification is a key psychological conduit through which leaders, with high Machiavellianism, motivate employees to withhold relevant ideas, information or opinions as a form of self-protection, based on fear. In addition, relational identification may be a causal mechanism that is relatively general across various types of behavioral choices such as organizational cynicism or citizenship behaviors that deteriorate or improve organizational effectiveness. By considering relational identification as a proximal psychological pathway influencing employees' behavioral choices, this study facilitates future research seeking interventions that might prove effective in ultimately reducing workplace silence.

Moreover, this study linked two conventionally independent research areas, leader's Machiavellianism and employee silence, thereby opening up new avenues for enriching the development of each field. Among the many negative consequences of leader's Machiavellianism to an organization, employee silence is the most serious. Employees who experience their leaders as being high in Machiavellianism perceive that their leaders act selfishly, manipulate and exploit others to achieve their long-term goals, as well as neither emotionally is attached to their subordinates nor concerned with the effects their behaviors have on other people (Rauthmann, 2012). Those leadership characteristics are clearly associated with difficulties in interpersonal relationships, which, in turn, lead to low trust in leader, relational identification and high quiescent silence. This finding places leader Machiavellianism as one important precedent to employee workplace silence.

Another key contribution of this study rests on the role of relational identification as a mediator of the link between leader Machiavellianism and employee silence. Traditionally, the positive effects of relational identification have been limited to trust in supervisor, organizational commitment and satisfaction (Carmeli et al., 2011). We have now expanded this to include the employee silence.

Given the call of broadening the criterion domain to include the interpersonal antecedents of employee silence (e.g. Xu et al., 2015), this study adds to literature through the examination of the moderating role of psychological distance.

One noteworthy finding of this research is the moderated mediation model that applied social exchange theory (Blau, 1964) to define the mediation path. This model provided a theoretical framework on how an independent variable (such as leader Machiavellianism) may affect the dependent variable (quiescent silence) through the mediator (relational identification). As for the moderator, psychological distance moderated the mediating effect of relational identification on the indirect relationship between leader Machiavellianism and employee silence. High levels of psychological distance increased the mediating effect of relational identification.

\subsection{Managerial implication and conclusion}

The findings of this study are consistent with the previous research results (Belschak et al., 2018; Gunnthorsdottir et al., 2002) that leader Machiavellianism has negative employee outcomes such as low job satisfaction and commitment as well as high organizational cynicism, turnover intention and workplace silence. This study has important implications for higher education management. The results highlight the importance of leader Machiavellianism, as it is positively related to employee silence. Leaders with high Machiavellianism are prone to exploit others, have lower quality relationships and take shortcuts or behave in unethical ways (Belschak et al., 2018). In terms of implications for organizations, these findings point to the importance of reinforcing an ethical context as well as to the significance of leader selection. Specifically, in order to ensure that Machiavellian leaders do not thrive in organizations, it is important to maintain an ethical context. If the context is unethical, or interpersonally ineffective, behaviors will likely turn out to be more salient and evaluated more negatively by coworkers (Erkutlu and Chafra, 2018). Thus, it is 
EJMBE

28,3

336

unlikely that Machiavellian leaders will be successful in advancing in a highly ethical context (Ruiz-Palomino et al., 2013).

The findings of this study suggest that relational identification acts as a link between leader's Machiavellianism and employee silence. Generally, employees consider managers who behave in a disrespectful and abusive manner as a burden. However, employees do not always react or speak up to their manager, even if (s)he behaves abusively (Burris, 2012). Employees, who perceive high relational identification, feel that they have been treated with dignity and respect, have trust in their leader and tend to show less negative consequences when confronted with a Machiavellian leader. Indeed, relational identification seems to work as a mediator on followers' negative reactions to Machiavellian leadership. Therefore, organizations should provide additional support and resource-based interventions to buffer abused employees' experience of low relational identification. For example, organizations could provide psychological consultation services to those victims and listen to their voice. Furthermore, employers could implement employee health progress program to detect the health status of their employees from time to time. Moreover, organizations could pay attention to leaders' Machiavellianism due to their detrimental effects. This is relevant not only when filling leader positions but also when dealing with existing leaders in the organization. In fact, existing leaders should be made aware of the effect their personality may have on their employees as well as receive training on effective leadership styles (e.g. transformational leadership) to cope with the potential negative effects of Machiavellianism in the workplace.

Given the goal of reducing the number of stresses in the workplace, acknowledging that a state of perceived leader Machiavellianism is stressful is a starting point for the design of preventative interventions. For instance, if perceived Machiavellian leadership is recognized as a factor creating low relational identification, human resources experts might include supportive leadership styles such as transformational, ethical or authentic leadership behaviors in curricula for management training programs. With respect to the goal of improved management of existing low level of employee identification with the leader, the characterization of leader Machiavellianism as a factor of low relational identification may benefit counseling and employee assistance initiatives. For instance, these programs may help employees recognize situations that lead to the perceptions of Machiavellian leadership behaviors as a contributing factor in their experience of low employee identification with the organization and the leader. As such, employees may be able to learn how to cope with their feelings of the perceived Machiavellianism.

Our research showed that high psychological distance increases the negative effect of leader's Machiavellianism on relational identification. Managers should pay more attention to the buffering role of psychological distance especially for those employees with low relational identification and showing workplace silence. For managers, this study shows that organizations, whose priority is to reduce silence, should design a workplace in which employees and their supervisors have an opportunity to work toward establishing common values. The presence of low psychological distance provides a fertile ground to create a more engaged workforce. This, in turn, reduces the likelihood that employees choose activities conflicting with the interests of their organization. A culture that embraces supportive leadership such as ethical, transformational or authentic leadership may be instrumental in this respect because supportive leaders tend to align followers' interests effectively with those of the organization (Stone et al., 2004). Conversely, organizations should be aware that when there is a high psychological distance between manager and his/her subordinates, the resulting lack of communication and control, as well as uncertainty might prompt subordinates to pursue activities that meet their personal interests only, even if these activities may harm their employing organization. At a more general level, top management should stimulate their employee base, across hierarchical ranks, to move away 
from viewing their personal goal setting through a self-interested lens. Instead, they should encourage employees to see themselves and supervisors as "partners" who share a set of common values and interests, with the ultimate objective of helping the organization meet its goals.

\section{Leader \\ Machiavellianism and follower silence}

\subsection{Limitations and future research}

One limitation of our study is that our sample was only drawn from universities in Turkey, thus external validity is a concern. Another limitation arises from the cross-sectional data, as no causal relationships can be established without longitudinal studies. Furthermore, the use of a self-rating scale could also hold social-desirability bias as participants have a tendency to give socially desirable responses instead of choosing responses that are reflective of their true feelings.

Future research can be conducted to address the limitations pertaining to this study. We call for continuing empirical research on the relationship between leader Machiavellianism and follower silence based on samples from universities that operate in other economies. As consensus can only be reached by accumulating evidence from a more representative mix of samples, we offer the current findings as a basis for further research. It would be even more meaningful to conduct longitudinal studies to examine how the changes in leader Machiavellianism affect workplace silence. Moreover, future leader Machiavellianism research might benefit from focusing on the role of context in reducing or exacerbating the impact of such leadership styles on work outcomes. In line with Johns' (2006) admonition on the importance of acknowledging and integrating the influence of context in research, we argue that situational factors such as perceived organizational politics or organizational culture may exert an important effect on employee behavior. Finally, yet importantly, future research can be conducted by using structural equation modeling (SEM) to test the relationship among the variables in this study in a single analysis instead of testing separate regression analyses. There are over a dozen methods of mediation and moderation analysis, most of them testing the statistical significance of a sequence of linear regression models (Baron and Kenny, 1986). By using SEM, simultaneous examination of direct and indirect relationships among constructs represented by multiple items can be conducted. Researchers have advocated the use of SEM techniques for assessing mediation (e.g. Preacher and Hayes, 2004) and empirically demonstrated their superiority over regression procedures (Iacobucci et al., 2007). Some SEM software packages now offer indirect effect tests using one of the above approaches for determining significance. Moreover, the SEM analysis approach provides model fit information about consistency of the hypothesized mediational model to the data. Since measurement error is a potential concern in mediation testing because of attenuation of relationships, approaches addressing this issue gain acceptance and popularity. SEM approach, in this regard, answers this need by removing measurement error from the estimation of the relationships among the variables.

\section{References}

Akın, U. and Ulusoy, T. (2016), "The relationship between organizational silence and burnout among academicians", International Journal of Higher Education, Vol. 5 No. 2, pp. 46-58.

Arbuckle, J.L. (2006), AMOS 7.0 User's Guide, SPSS, Chicago, IL.

Argyris, C. and Schon, D. (1978), Organizational Learning: A Theory of Action Approach, Addison Wesley, Reading, MA.

Ashforth, B.E. and Anand, V. (2003), "The normalization of corruption in organizations", Research in Organizational Behavior, Vol. 25 No. 1, pp. 1-52. 
EIMBE 28,3

Baron, R.M. and Kenny, D.A. (1986), "The moderator-mediator variable distinction in social psychological research: conceptual, strategic, and statistical considerations", Journal of Personality and Social Psychology, Vol. 51 No. 6, pp. 1173-1182.

Bass, B.M. (1990), Bass and Stogdill's Handbook of Leadership, Free Press, New York, NY.

Belschak, F.D., Muhammad, R.S. and Den Hartog, D.N. (2018), "Birds of a feather can butt heads: when Machiavellian employees work with Machiavellian leaders”, Journal of Business Ethics, Vol. 151 No. 1, pp. 613-626.

Blau, P.M. (1964), Exchange and Power in Social Life, Wiley, New York, NY.

Brinsfield, C.T. (2013), "Employee silence motives: investigation of dimensionality and development of measures", Journal of Organizational Behavior, Vol. 34 No. 5, pp. 671-697.

Burris, E.R. (2012), "The risks and rewards of speaking up: managerial responses to employee voice", Academy of Management Journal, Vol. 55 No. 1, pp. 851-875.

Carla, J. (1996), "Recreating the indifferent employee”, HRM Magazine, August, pp. 76-81.

Carmeli, A., Atwater, L. and Levi, A. (2011), "How leadership enhances employees' knowledge sharing: the intervening roles of relational and organizational identification", The Journal of Technology Transfer, Vol. 36 No. 3, pp. 257-274.

Chin, W.W. (1998), "The partial least squares approach to structural equation modeling", Modern Methods for Business Research, Vol. 295 No. 2, pp. 295-336.

Christie, R. and Geis, F.L. (1970), Machiavellianism, Academic Press, New York, NY.

Cokley, K., Stone, S., Krueger, N., Bailey, M., Garba, R. and Hurst, A. (2018), "Self-esteem as a mediator of the link between perfectionism and the impostor phenomenon", Personality and Individual Differences, Vol. 135 No. 1, pp. 292-297.

Dahling, J.J., Whitaker, B.G. and Levy, P.E. (2009), "The development and validation of a new Machiavellianism scale", Journal of Management, Vol. 35 No. 2, pp. 219-257.

Dedahanov, A.T. and Rhee, J. (2015), "Examining the relationships among trust, silence and organizational commitment", Management Decision, Vol. 53 No. 8, pp. 1843-1857.

Dirks, K.T. (2000), "Trust in leadership and team performance: evidence from NCAA basketball", Journal of Applied Psychology, Vol. 85 No. 6, pp. 1004-1012.

Dyne, L.V., Ang, S. and Botero, I.C. (2003), "Conceptualizing employee silence and employee voice as multidimensional constructs", Journal of Management Studies, Vol. 40 No. 6, pp. 1359-1392.

Erkutlu, H. and Chafra, J. (2016), "Impact of behavioral integrity on workplace ostracism: the moderating roles of narcissistic personality and psychological distance", Journal of Applied Research in Higher Education, Vol. 8 No. 2, pp. 222-237.

Erkutlu, H. and Chafra, J. (2018), "Despotic leadership and organizational deviance: the mediating role of organizational identification and the moderating role of value congruence", Journal of Strategy and Management, Vol. 11 No. 2, pp. 150-165.

Erkutlu, H.V. and Chafra, J. (2017), "Leader narcissism and subordinate embeddedness: the moderating roles of moral attentiveness and behavioral integrity", EuroMed Journal of Business, Vol. 12 No. 2, pp. 146-162.

Farzaneh, J., Dehghanpour Farashah, A. and Kazemi, M. (2014), "The impact of person-job fit and person-organization fit on OCB: the mediating and moderating effects of organizational commitment and psychological empowerment", Personnel Review, Vol. 43 No. 5, pp. 672-691.

Geis, F.L. and Moon, T.H. (1981), "Machiavellianism and deception", Journal of Personality and Social Psychology, Vol. 41 No. 5, pp. 766-775.

Gkorezis, P. and Bellou, V. (2016), "The relationship between workplace ostracism and information exchange: the mediating role of self-serving behavior", Management Decision, Vol. 54 No. 3 , pp. $700-713$. 
Gkorezis, P., Petridou, E. and Xanthiakos, P. (2014), "Leader positive humor and organizational cynicism: LMX as a mediator”, Leadership \& Organization Development Journal, Vol. 35 No. 4, pp. 305-315.

Gunnthorsdottir, A., McCabe, K. and Smith, V. (2002), "Using the Machiavellianism instrument to predict trustworthiness in a bargaining game", Journal of Economic Psychology, Vol. 23 No. 1, pp. 49-66.

Hayes, A.F. and Preacher, K.J. (2010), "Estimating and testing indirect effects in simple mediation models when the constituent paths are nonlinear", Multivariate Behavioral Research, Vol. 45 No. 1, pp. 627-660.

He, P., Peng, Z., Zhao, H. and Estay, C. (2017), "How and when compulsory citizenship behavior leads to employee silence: a moderated mediation model based on moral disengagement and supervisorsubordinate guanxi views", Journal of Business Ethics, Vol. 1 No. 1, pp. 1-16.

Iacobucci, D., Saldanha, N. and Deng, X. (2007), "A meditation on mediation: evidence that structural equations models perform better than regressions", Journal of Consumer Psychology, Vol. 17 No. 2, pp. 139-153.

Johns, G. (2006), "The essential impact of context on organizational behavior", Academy of Management Review, Vol. 31 No. 1, pp. 386-408.

Kark, R., Shamir, B. and Chen, G. (2003), "The two faces of transformational leadership: empowerment and dependency", Journal of Applied Psychology, Vol. 88 No. 2, pp. 246-255.

Kenworthy, J.B. and Jones, J. (2009), "The roles of group importance and anxiety in predicting depersonalized ingroup trust", Group Processes \& Intergroup Relations, Vol. 12 No. 2, pp. 227-239.

LeBreton, J.M., Wu, J. and Bing, M.N. (2009), "The truth(s) on testing for mediation in the social and organizational sciences", in Lance, C.E. and Vandenberg, R.J. (Eds), Statistical and Methodological Myths and Urban Legends, Routledge, New York, NY, pp. 107-141.

Lord, R.G., Brown, D.J. and Freiberg, S.J. (1999), "Understanding the dynamics of leadership: the role of follower self-concepts in the leader/follower relationship", Organizational Behavior and Human Decision Processes, Vol. 78 No. 3, pp. 167-203.

Milliken, F.J. and Lam, N. (2009), "Making the decision to speak up or to remain silent: implications for organizational learning", in Greenberg, J., Edwards, M.S. and Brinsfield, C.T. (Eds), Voice and Silence in Organizations, Emerald Group Publishing, London, pp. 225-244.

Milliken, F.J., Morrison, E.W. and Hewlin, P.F. (2003), “An exploratory study of employee silence: issues that employees don't communicate upward and why", Journal of Management Studies, Vol. 40 No. 6, pp. 1453-1476.

Morrison, E.W. and Rothman, N.B. (2009), "Silence and the dynamics of power", in Greenberg, J., Edwards, M.S. and Brinsfield, C.T. (Eds), Voice and Silence in Organizations, Emerald Group Publishing, Bingley, pp. 111-133.

Napier, B.J. and Ferris, G.R. (1993), "Distance in organizations”, Human Resource Management Review, Vol. 3 No. 4, pp. 321-357.

O’Boyle, E.H., Forsyth, D.R., Banks, G.C. and McDaniel, M.A. (2012), "A meta-analysis of the dark triad and work behavior: a social exchange perspective", Journal of Applied Psychology, Vol. 97 No. 3, pp. 557-579.

Odle, T.K. (2014), "The implications of distance and envy in organizations: an exploration of leader-member exchange and organizational citizenship behaviors", unpublished master's thesis, The University of Tennessee, Knoxville, TN.

Parker, S.K., Bindl, U.K., Van Dyne, L. and Wong, S.F. (2009), "Measuring motives for silence", paper presented at the Annual Meeting of the Academy of Management, Chicago, IL.

Pinder, C.C. and Harlos, K.P. (2001), "Employee silence: Quiescence and acquiescence as responses to perceived injustice", in Ferris, G.R. (Ed.), Research in Personnel and Human Resources Management, Emerald Group Publishing Limited, Greenwich, CT, pp. 331-369. 
EIMBE 28,3
Podsakoff, P.M. and Organ, D.W. (1986), "Self-reports in organizational research: problems and prospects", Journal of Management, Vol. 12 No. 4, pp. 531-544.

Pratt, M.G. (1998), "To be or not to be? Central questions in organizational identification", in Whetten, D.A. and Godfrey, P.C. (Eds), Identity in Organizations, Building Theory Through Conversations, Sage, Thousand Oaks, CA, pp. 171-207.

Preacher, K.J. and Hayes, A.F. (2004), "SPSS and SAS procedures for estimating indirect effects in simple mediation models", Behavior Research Methods, Instruments, \& Computers, Vol. 36 No. 4, pp. 717-731.

Preacher, K.J., Rucker, D.D. and Hayes, A.F. (2007), "Addressing moderated mediation hypotheses: theory, methods, and prescriptions", Multivariate Behavioral Research, Vol. 42 No. 1, pp. $185-227$.

Rauthmann, J.F. (2012), "The Dark Triad and interpersonal perception: similarities and differences in the social consequences of narcissism, Machiavellianism, and psychopathy", Social Psychological and Personality Science, Vol. 3 No. 4, pp. 487-496.

Ruiz-Palomino, P., Martínez-Cañas, R. and Fontrodona, J. (2013), "Ethical culture and employee outcomes: the mediating role of person-organization fit", Journal of Business Ethics, Vol. 116 No. 1, pp. 173-188.

Sallis, E. (2014), Total Quality Management in Education, Routledge, London.

Schepers, D.H. (2003), "Machiavellianism, profit, and the dimensions of ethical judgment: a study of impact", Journal of Business Ethics, Vol. 42 No. 4, pp. 339-352.

Shrout, P.E. and Bolger, N. (2002), "Mediation in experimental and nonexperimental studies: new procedures and recommendations", Psychological Methods, Vol. 7 No. 4, pp. 422-445.

Sluss, D.M. and Ashforth, B.E. (2007), "Relational identity and identification: defining ourselves through work relationships", Academy of Management Review, Vol. 32 No. 1, pp. 9-32.

Solomon, R.C. and Flores, F. (2001), Building Trust, Oxford University Press, New York, NY.

Stone, A.G., Russell, R.F. and Patterson, K. (2004), "Transformational versus servant-leadership: a difference in leader focus", Leadership \& Organizational Development Journal, Vol. 25 No. 4, pp. 349-361.

Story, J.S. and Barbuto, J.E. Jr (2011), “Global mindset: a construct clarification and framework”, Journal of Leadership \& Organizational Studies, Vol. 18 No. 3, pp. 377-384.

Tangirala, S. and Ramanujam, R. (2008), "Employee silence on critical work issues: the cross level effects of procedural justice climate", Personnel Psychology, Vol. 61 No. 1, pp. 37-68.

The Council of Turkish Higher Education (2018), "University statistics", available at: https://istatistik. yok.gov.tr (accessed September 18, 2018).

Thompson, G., Buch, R. and Kuvaas, B. (2017), "Political skill, participation in decision-making and organizational commitment", Personnel Review, Vol. 46 No. 4, pp. 740-749.

Torres, A. and Bligh, M. (2012), "How far can I trust you? The impact of distance and cultural values on leaders' trustworthiness", Journal of Leadership, Accountability and Ethics, Vol. 9 No. 2, pp. 23-38.

Umphress, E.E., Mitchell, M.S. and Bingham, J.B. (2010), "Unethical behavior in the name of the company: the moderating effect of organizational identification and positive reciprocity beliefs on unethical pro-organizational behavior", Journal of Applied Psychology, Vol. 95 No. 4, pp. 769-780.

Vigoda-Gadot, E. and Talmud, I. (2010), "Organizational politics and job outcomes: the moderating effect of trust and social support", Journal of Applied Social Psychology, Vol. 40 No. 11, pp. 2829-2861.

Walumbwa, F.O. and Hartnell, C.A. (2011), "Understanding transformational leadership-employee performance links: the role of relational identification and self-efficacy", Journal of Occupational and Organizational Psychology, Vol. 84 No. 1, pp. 153-172. 
Walumbwa, F.O. and Schaubroeck, J. (2009), "Leader personality traits and employee voice behavior: mediating roles of ethical leadership and work group psychological safety”, Journal of Applied Psychology, Vol. 94 No. 5, pp. 1275-1286.

Wang, Y.D. and Hsieh, H.H. (2013), "Organizational ethical climate, perceived organizational support, and employee silence: a cross-level investigation”, Human Relations, Vol. 66 No. 6, pp. 783-802.

Wu, M., Huang, X., Li, C. and Liu, W. (2012), "Perceived interactional justice and trust-in-supervisor as mediators for paternalistic leadership", Management and Organization Review, Vol. 8 No. 1, pp. 97-121.

Xu, A.J., Loi, R. and Lam, L.W. (2015), "The bad boss takes it all: how abusive supervision and leadermember exchange interact to influence employee silence", The Leadership Quarterly, Vol. 26 No. 5, pp. 763-774.

Yagil, D. (1998), "Charismatic leadership and organizational hierarchy: attribution of charisma to close and distant leaders", The Leadership Quarterly, Vol. 9 No. 2, pp. 161-176.

Yang, J. and Mossholder, K.W. (2010), "Examining the effects of trust in leaders: a bases-and-foci approach”, The Leadership Quarterly, Vol. 21 No. 1, pp. 50-63.

Yoon, D.J. (2017), "Compassion momentum model in supervisory relationships", Human Resource Management Review, Vol. 27 No. 1, pp. 473-490.

Zagenczyk, T.J., Cruz, K.S., Woodard, A.M., Walker, J.C., Few, W.T., Kiazad, K. and Raja, M. (2013), "The moderating effect of Machiavellianism on the psychological contract breach-organizational identification/disidentification relationships", Journal of Business and Psychology, Vol. 28 No. 3, pp. 287-299.

\section{Appendix}

(1) Machiavellian Personality Scale (Dahling et al., 2009):

- My department chair believes that lying is necessary to maintain a competitive advantage over others.

- The only good reason to talk to others is to get information that my department chair can use to his/her benefit.

- My department chair is willing to be unethical if he/she believes it will help him/her succeed.

- My department chair is willing to sabotage the efforts of other people if they threaten his/ her own goals.

- My department chair would cheat if there was a low chance of getting caught.

- My department chair likes to give the orders in interpersonal situations.

- My department chair enjoys having control over other people.

- My department chair enjoys being able to control the situation.

- Status is a good sign of success in life.

- Accumulating wealth is an important goal for him/her.

- My department chair wants to be rich and powerful someday.

- People are only motivated by personal gain.

- My department chair dislikes committing to groups because he/she doesn't trust others.

- Team members backstab each other all the time to get ahead.

- If my department chair shows any weakness at work, other people will take advantage of it.

- Other people are always planning ways to take advantage of the situation at my expense. 
EJMBE

28,3

(2) Quiescent silence (Parker et al., 2009):

- I would not want to hurt my career.

- I would not want to damage my reputation.

- I would not want to hurt my position in the team.

- I would not want to be seen as difficult or rude.

- I would not want to damage my relationship with others.

(3) Relational identification (Walumbwa and Hartnell, 2011):

- When someone criticizes my department chair, it feels like an insult to me.

- I am interested in what others think about my department chair.

- When I talk about my department chair, I usually say "we" rather than "him or her."

- I share the success of my department chair.

- I have a sense of partnership with my department chair.

- I am proud to tell others I work with this department chair.

- I praise my department chair when speaking with friends.

- I have a mutually beneficial relationship with my department chair.

- I respect the views and suggestions of my department chair.

- The values of my department chair are consistent to my own.

(4) Psychological distance (Napier and Ferris, 1993):

- I feel very similar to my department chair.

- My department chair and I share much in common.

- My department chair is not that different from me.

Corresponding author

Hakan Erkutlu can be contacted at: erkutlu@nevsehir.edu.tr

For instructions on how to order reprints of this article, please visit our website: 